\title{
Parámetros para el levantamiento catastral de criptas, cementerios y camposantos en zonas urbanas y rurales. (Caso de estudio cantón Loja)
}

\section{Parameters for the cadastral survey of crypts, cemeteries and graveyards in urban and rural areas. (Case study canton Loja)}

Freddy Michael Vite Valverde

Pedro José Álvarez Loaiza

Universidad Internacional del Ecuador, Ecuador

Micaela Alejandra Alvear González

Consultor Independiente, Ecuador

Autor para correspondencia: frviteva@uide.edu.ec

Fecha de recepción: 13 de Octubre 2017 - Fecha de aceptación: 15 de Febrero de 2018

Resumen: Los cementerios son lugares destinados a la sepultura de restos mortales; dependiendo de la ubicación geográfica y la cultura, los cuerpos se depositan en sarcófagos, féretros, o ataúdes, para luego ser enterrados en mausoleos, nichos, criptas, o bajo tierra; sin embargo en la actualidad no se ha logrado un manejo adecuado en lo referente a la organización y actualización de estos espacios fúnebres por parte de los GAD'S Municipales, tanto en las zonas urbanas y rurales, lo que impide darles un mejor manteniendo; por ello se ha considerado emplear una metodología para realizar un diagnóstico que a su vez permita levantar el catastro del área de estudio. Para obtener la información se tomaron en consideración las siguientes fases: 1) revisión bibliográfica, 2) registro de información mediante una ficha de inventario; 3) elaboración de un inventario de cementerios, criptas y camposantos, 4) Estudio de la capacidad instalada y utilizada. Los resultados obtenidos después de proceso fueron los siguientes: diagnóstico de la situación actual de las criptas, cementerios y camposantos, creación de un inventario y un catastro de criptas, cementerios y camposantos. Todo esto se realizó mediante el método exploratorio ya que este permitió definir la situación actual de las criptas, cementerios y campo santos; además del método de observación directa y científica los cuales ayudaron a analizar el estado de conservación de los mismos.

Palabras Clave: criptas; cementerios; camposantos; inventario; catastro; diagnóstico

Abstract: Cemeteries are places where mortal remains are destined for burial. Depending on the geographical location and the culture, bodies are deposited in caskets or coffins; then these caskets are buried in mausoleums, niches, crypts or underground. However, presently, adequate management has not been achieved by the Municipal GAD'S with regard to the organization and updating of these funeral spaces, both in urban and rural areas, which prevents them from giving these burial sites better maintenance. For that reason, it has been considered to utilize a methodology to diagnose that allows the creation of a land register in the area of study. In order to obtain the information, the following phases were taken into account: 1) bibliographic review; 2) recording information through an inventory form; 3) preparation of an inventory of cemeteries, 
crypts and churchyards; 4) Study of potential capacity and its uses. The results obtained after the process were: diagnosis of the current situation of crypts, cemeteries and churchyards, creation of an inventory and a registry of crypts, cemeteries and churchyards. All this was done by the exploratory method, since this allowed it to define the current situation of the crypts cemeteries and churchyards. In addition, the direct and scientific method of observation was use, which helped to analyze their conservation status.

Key words: crypts; cemeteries; churchyards; inventory; land register; diagnostic

\section{Introducción}

Se cree que el ser humano tenía la costumbre de enterrar a su familiares fallecidos desde hace 100.000 años, los primeros difuntos fueron enterrados en casas, sin embargo debido a la propagación de gérmenes y enfermedades se concluyó esta modalidad en el siglo XV, para principios del siglo XVI se comienza con la construcción de los primeros cementerios que se conocen actualmente, en sus inicios los cristianos enterraron los restos de sus mártires en catatumbas, pero con el tiempo estas ya no fueron suficientes para dar cabida a la sepultura, por lo que se tuvieron que buscar otras alternativas de entierro, así es como por donación de algunas personas de clase alta se fueron estableciendo los cementerios, donde se construían altares y capillas que les permitían realizar ceremonias fúnebres, con el tiempo hubieron excepciones para que personas nobles pudieran ser enterradas dentro de las iglesias dando paso a las primeras criptas las cuales fueron creciendo hacia finales del siglo XVI debido a los pequeños que resultaban los cementerios.

A pesar de décadas de creación de estos establecimientos destinados a la sepultara no se ha logrado un manejo adecuado, por ello se ha considerado aplicar una metodología que permita realizar un catastro de las criptas, cementerios y camposantos de las zonas urbanas y rurales a través de una ficha técnica donde consta la siguiente información: 1)categoría, tipo y subtipo tomando en consideración estas categorías de las fichas de jerarquización de atractivos del ministerio de turismo, ya que se considera que la sepultura es un acto cultural en muchas comunidades; 2) Provincia; 3) Cantón; 4) Parroquia; 5) Ubicación; 6) Coordenadas; 7) Extensión; 8) Estado de Conservación; 9) Descripción; 10) Costos; 11) Administración. Además, fue necesario utilizar métodos, técnicas, y herramientas como: el método exploratorio, y método de observación científica, además de técnicas de investigación directa, y fichaje, entrevistas; y herramientas como la Guía para el levantamiento de atractivos turísticos del Ecuador.

Hipótesis: La elaboración del catastro de las criptas, cementerios y camposantos ayudará a una mejor administración de estos establecimientos fúnebres, respecto a la capacidad utilizada e instalada.

Explore la importancia del problema: En la actualidad no se ha logrado un manejo adecuado en lo referente a la organización y actualización de las criptas, cementerios y camposantos, por parte de los GAD'S Municipales, tanto en las zonas urbanas y rurales, lo que impide darles un mejor manteniendo; por ello se ha considerado emplear una metodología para realizar un diagnóstico que a su vez permita levantar el catastro del área de estudio.

\section{Materiales}

\section{Metodología}




\section{Campo:}

Cámara digital (1), Celulares (1), GPS (1), Credenciales, Libros, Libreta de apuntes, Vehículo, Esferos

\section{Oficina:}

Computadora, Impresora, Flash memory, hojas

\section{Métodos}

\section{Explicativo:}

Son aquellos trabajos donde la preocupación, se centra en determinar los orígenes o las causas de un determinado conjunto de fenómenos. (Ramos, 2008)

\section{Inductivo:}

Es el razonamiento que, partiendo de casos particulares, se eleva a conocimientos generales. Este método permite la formación de hipótesis, investigación de leyes científicas, y las demostraciones. La inducción puede ser completa o incompleta. (Ramos, 2008)

\section{Deductivo:}

Mediante ella se aplican los principios descubiertos a casos particulares, a partir de un enlace de juicios. El papel de la deducción en la investigación es doble:

- Primero consiste en encontrar principios desconocidos, a partir de los conocidos.

- También sirve para descubrir consecuencias desconocidas, de principios conocidos. (Ramos, 2008)

\section{Sintético:}

Es un proceso mediante el cual se relacionan hechos aparentemente aislados y se formula una teoría que unifica los diversos elementos. Consiste en la reunión racional de varios elementos dispersos en una nueva totalidad, este se presenta más en el planteamiento de la hipótesis. El investigador sintetiza las superaciones en la imaginación para establecer una explicación tentativa que someterá a prueba. (Ramos, 2008)

\section{Técnicas}

\section{Observación directa:}

Esta técnica permitió realizar un diagnóstico de los cementerios del cantón Loja, mediante una ficha técnica donde se ubica la categoría, tipo y subtipo, tomadas de las fichas de jerarquización de atractivos del Ministerio de Turismo, debido a que el entierro es considerado 
en el medio como una costumbre cultural en la localidad; adicionalmente se levantaron datos sobre: la localización de los cementerios, la extensión de los cementerios, la ubicación y coordenadas, estado de conservación, breve descripción de los servicios, costos del servicio y administración

\section{Entrevistas:}

Se realizaron entrevistas a los administradores de los establecimientos fúnebres con el fin de obtener información importante para el catastro.

\section{Herramientas:}

- Ficha de Diagnostico para criptas, cementerios y camposantos.

- Guía para el levantamiento de atractivos turísticos del Ecuador.

\section{Resultados}

\section{Fase 1: Revisión Bibliográfica:}

\subsection{Medio ambiente:}

Según Calvo y Angulo, 1997 Para los técnicos medioambientales (ingenieros, ecólogos, psicólogos medio ambientales, etc) el medio ambiente es el entorno vital, el conjunto de condiciones físicas, químicas, biológicas, psíquicas que rodean un organismo.

El ámbito de la conducta, lo que percibe el individuo, es el hábitat. Dicho esto, se deduce que el medio ambiente visto desde su aspecto científico, es una cosa, y visto desde el hombre $u$ otra especie animal es otra, se dice que el científico percibe el medio ambiente mediante sus datos (clima, contaminación, paisaje, luz, ecosistemas, complejidad), mientras que la persona no experta lo percibe con sus sentidos (color, olor, paisaje, contaminación, etc).

\subsection{Contaminación:}

"La contaminación se define como una alteración del estado natural de un medio debida a la introducción de un agente nocivo y ajeno al medio. Este agente contaminante es el encargado de causar inestabilidad, desorden, daño o malestar en el ecosistema, en el medio físico o en un ser vivo". (Pascual, 2015)

\subsection{Impacto ambiental:}

"Se llama así a los daños causados por cualquier accionar humano que modifique las condiciones de supervivencia del ecosistema. Estas acciones causan daños irreversibles sobre el medio tanto social como natural”. (Pilco, 2012)

\subsection{Huella ecológica:}


"La huella ecológica permite evaluar el impacto que generan los estándares de consumo de los seres humanos, frente a los recursos naturales existentes en el medio. La huella ecológica se la mide en unidad de hectáreas globales" (hag.) (MAE, 2015)

\subsection{Definición de cementerio:}

"La palabra cementerio se deriva del vocablo griego bizantino cuyo significado "dormitorio", posteriormente llega al latín tardío como coemeterǐum, y finamente en lengua española toma el significado de cementerio; este concepto se utiliza para llamar al espacio donde se realiza el entierro de los cadáveres". (Porto, 2016).

\subsection{Las formas de enterramiento:}

Según Flores, 2016 Han variado con el transcurso del tiempo, como un elemento más, propio de cada cultura, tradición o época histórica que hacen la diferencia de la una de la otra. Los cementerios demuestran de un modo u otro su mundo, su sociedad, de ahí su importancia e interés desde sus comienzos.

Estos lugares sagrados, que se han conformado, no solo sirven para el estudio de la muerte sino también para el de la vida, ya que se constituyen en la expresión de una cultura y de un momento histórico, prueba de ello son las pirámides de Egipto, las catacumbas, los sarcófagos, las capillas funerarias o los cementerios contemporáneos.

Si establecemos un recorrido histórico se aprecia las diferencias y los cambios sufridos con el paso del tiempo que han sobrellevado las formas de entierro. La vida y la muerte tenían espacios claramente diferenciados, es por este motivo que los lugares de entierro se situaban fuera de las ciudades, pero no muy alejados de ellos, se los ubicaba a lo largo de las carreteras evitando el olvido de los seres queridos que partieron. Todo esto se lo realizaba con el objetivo de evitar el riesgo de contagio de enfermedades que podían emanar estos lugares infecciosos.

Pero con el paso del tiempo este fenómeno se fue transformando por el cambio de mentalidad y de creencias. Con la llegada del cristianismo surgía la necesidad de un entierro cerca de lugares sagrados o de personajes santos. "Así surgen las catacumbas, cavidades subterráneas en las cuales los cristianos perseguidos se hacían enterrar lejos de las necrópolis.

\subsection{Los diferentes modos de enterrar:}

"Pretenden perdurar en la memoria de la historia a sus protagonistas, han sido rescatados por medio de estudios arqueológicos ya que no dejaron testimonios escritos de la gestión del hecho en sí mismo. Por el contrario, son las inscripciones de las tumbas y las representaciones iconográficas de ellas, las que dan cuenta de lo que el difunto hizo y representó en vida." (VALOR, 2012)

\subsection{En Europa continental:}


Según Jiménez, 2012 Los cuerpos usualmente eran enterrados en un sepulcro total hasta que se descomponían. Los huesos entonces eran exhumados y almacenado en ossuaries, cualquiera a lo largo de las paredes de la galería del cementerio, o dentro de la iglesia debajo de las losas del piso y detrás de las paredes. En la mayoría de las culturas los que eran sumamente ricos, tenían profesiones importantes, eran parte de la nobleza o estaban de cualquier otro alto estatus social se enterraban generalmente en criptas individuales dentro o debajo del lugar relevante de la adoración con una indicación del nombre de los difuntos, la fecha de la muerte y otros datos biográficos.

\section{9. ¿Cómo será tratado el cuerpo después de la muerte?:}

"Duelo por la muerte de un ser querido: creencias culturales y espirituales", (s/f.). Palermo.edu. El trato de cuerpo después de la muerte depende de las creencias, costumbres, tradiciones, la sociedad, el género y edad y la posibilidad económica.

Los rituales funerarios como entierros, cremaciones e inhumaciones no suelen ser un procedimiento sencillo; sino que involucran tomas de decisiones, y pasos a seguir antes, durante y después del entierro. Los arqueólogos tienden a reducir los rituales funerarios a la muerte, olvidando de los procesos que existen al post entierro, donde también se reflejan las creencias, tradiciones y principios básicos de la sociedad.

El trabajo del duelo, así como la despedida que el familiar deberá hacer encuentran mayores dificultades emocionales y mentales lo cual pueden complicar el duelo tornándolo patológico o crónico. Todos estos aspectos hacen que la muerte traumática vuelva más doloroso el duelo para los seres queridos del fallecido tornando más difícil la tarea del duelo no solo por la imposibilidad de anticipar la muerte del ser amado sino por el "estrés post traumático" que sufre quien debe afrontar una muerte inesperada.

\subsection{Catal huyuc:}

"Huyuk Catal Religión en Evolución (6000 AC)", (s/f.). Ojoeternidad.blogspot Este antiguo asentamiento de los períodos neolítico y católico ha sido el conjunto urbano más grande y mejor preservado de la época neolítica en el Oriente. Catal Huyuc viene del turco çatal: ‘tenedor', y höyük: ‘túmulo'. En su apogeo este asentamiento llegó a cubrir 13 hectáreas.

La característica que más llama la atención en esta ciudad es que sus casas se encuentran juntas unas con otras, por lo que no existen calles. Para que los habitantes pudieran movilizarse dentro de la cuidad, iban por una red de escaleras construidas en el techo, esta inusual característica les permitía defender la cuidad.

Esta cultura mantenía un punto de vista religioso, desarrollando rituales funerarios muy singulares. Los muertos eran llevados a las afueras de la cuidad, y los buitres consumían sus restos, cuando quedaban solo los huesos, estos eran recogidos y llevados a las casas de los familiares, donde se los ubicaba dentro de grandes cajas, que eran al usadas como camas o sillas, de esta manera los Catal Huyuk conservaban lo muertos dentro de sus viviendas, ellos creían que de esta manera encontrarían la protección de sus antepasados. 
No cabe duda que la religión influyo de alguna manera en la organización primitiva de Catal Huyuc, pues las diferentes clases de inhumaciones dan idea de una creencia en el más allá, lo cual se desprende de las cámaras sepulcrales y de la posición de los muertos. Todas las viviendas de 3500 a.C. tenían adoratorio y un lugar para depositar a sus familiares que murieron.

\subsection{Mesopotamia:}

Según Pollock, 1999 En el mundo Mesopotámico lo que no fue inalterable hasta la conquista musulmana fue su religión que ha dominado y permanece hasta ahora. Esta religión se basó en el principio de las fuerzas de la naturaleza que se identifican con los dioses es así que a todos los elementos de la naturaleza se les da nombres: el dios del agua es Enlil, el del cielo Anu y el de la tierra Enki. Van tomando forma, en símbolos y terminan plasmándose en forma humana.

Los mesopotámicos creían espíritus maléficos y demonios, pensaban que influirían en el arte, pues hay numerosas representaciones artísticas, con el objetivo de espantar a estos espíritus ya que se pensaban que eran la razón de enfermedades, entre otras cosas. La magia y la astrología en Mesopotamia tuvieron un auge ya que tenían una relación directa con la religión, todos estos conocimientos fueron trasmitidos a otros pueblos.

Los templos son grandes complejos que con el pasar del tiempo se han ido desarrollando a través de las distintas épocas. No es sólo una institución religiosa, sino también política y administrativa. Se han excavado centenares de sepulcros en diversas partes de Mesopotamia, revelando información sobre esta cultura y sus hábitos y sus formas de entierro. A la mayoría de la gente los enterraron en sepulcros de la familia debajo de sus casas como se dio en la cultura Catalhuyuk, junto con algunas posesiones.

También se han encontrado envueltos en esteras y alfombras además a los niños difuntos se colocaron en "tarros grandes" que fueron situados en la capilla familiar. El otro resto se ha encontrado enterrado en la ciudad, en cementerios comunes. 17 sepulcros se han encontrado con los objetos muy preciosos en ellos, se asume que estos llegaron a ser sepulcros reales.

\subsection{Ouroborus:}

"Ouroborus", (s/f.). En Significados.com El ouroborus es una emblemática serpiente, se cree que su origen se dio en el antiguo Egipto y Grecia, representada con su cola siendo devorada por su boca, y renaciendo continuamente. Un diagnóstico y alquímico símbolo, Ouroboros expresa la unidad de todas las cosas, materiales y espirituales, que nunca desaparecen, pero constantemente cambian de forma en un ciclo eterno de destrucción y recreación.

\subsection{Costumbres Funerarias del Antiguo Egipto:}

Según Donald, 2001 Los numerosos eufemismos literarios y la falta de representaciones en el arte muestran el disgusto de los egipcios por la muerte. En el ánimo de mitigar este evento inevitable, instauraron un elaborado ritual funerario. 
No solo los reyes adquirían estatus divino tras la muerte sino que, desde finales del Reino Antiguo el hombre común ya pudo acceder a la otra vida tras la revolución en el culto funerario. Un difunto se transformaba en ntrr (dios) por medio de los rituales de la momificación y el entierro, los que incluían la ceremonia de apertura de la boca, etc.

\subsection{Momificación:}

“El vendado del cuerpo, imitando la reunificación del cadáver de Osiris, era el símbolo de la inminencia de la muerte y a la vez la transfiguración a un nuevo cuerpo. La colocación del cadáver momificado en el ataúd era simbólicamente realizada en los brazos de la diosa Nut, de modo que este naciera nuevamente". (Donald, 2001)

\subsection{Rituales de purificación, unción y apertura de la boca:}

Según Donald, 2001: El vertido de agua, tanto por su calidad de dadora de vida como por la de purificación, era parte de cada ritual. El cadáver, desecado primeramente o no, debía ser lavado (en la tienda de purificación) y luego ungido y vendado. Siete aceites sagrados utilizados en la unción son conocidos desde la primera dinastía.

Los últimos ritos antes del enterramiento eran realizados por el sacerdote sem, quien ofrecía libaciones e incienso y realizaba el ritual de apertura de la boca frente a la momia para renovar sus facultades: abrir la boca, la nariz, los ojos y los oídos mediante la presentación de herramientas rituales sobre los orificios, mientras se mataba un buey y era ofrecida una pierna y el corazón al difunto o su imagen como parte del proceso de revivificación. Este ritual podía realizarse sobre la momia o una estatua del muerto y, por medio del uso de hechizos y gestos se lograba animar la imagen y habilitar al ka (espíritu) del difunto para consumir las ofrendas que le serían traídas. El difunto, al igual que los dioses, necesitaba sustento diario que era provisto por medio del ritual de las ofrendas.

Las tumbas estaban equipadas con un área en las que podían ser hechas las ofrendas al difunto. Luego del ritual de ofrendas el difunto junto a su imagen era colocado en la tumba. Una liturgia acompañante llena de plegarias y hechizos era realizada por los escribas lectores. El ritual era acompañado de música y danzas acrobáticas en la entrada de la tumba, al igual que los gritos de las plañideras. El jener o grupo musical de la diosa Hathor, la dama de occidente, anunciaba quizás a la propia divinidad que recibiría al difunto en el inframundo y a la vez lo renovaría, probablemente también cargaba sexualmente la atmósfera, toda vez que el muerto necesitaba renacer hacia la otra vida.

\subsection{Enterramiento:}

Donald, 2001 La mastaba del Reino Antiguo consistía en un nicho de ofrendas ubicado en el extremo sur del lado este y más tarde evolucionó hacia una capilla de ofrendas más elaborada dentro de la propia mastaba. Una cámara dentro de la mastaba contenía una estatua del ka (espíritu) del difunto y servía como otro punto focal de las ofrendas. Posterior al Reino 
Antiguo, estas estatuas eran habitualmente ubicadas en capillas separadas cerca de los templos de las divinidades.

Las tumbas excavadas en la roca incluían una capilla subterránea, la que contenía una estela votiva del difunto en la que aparecían su nombre y títulos. También se podía mostrar al fallecido frente a una mesa de ofrendas o recibiendo ofrendas de sus familiares. Las ofrendas eran depositadas en una mesa al frente de la estela.

\subsection{El ritual de las ofrendas:}

Según Donald, 2001 El ritual de las ofrendas incluía la recitación de la fórmula de ofrenda, conocida como ḥtp-dj-nswt ("Una ofrenda que el rey da"). Ya que, según la teología egipcia, solo el rey podía hacer ofrendas a los dioses, cada vez que una ofrenda era dada, el oferente debía decir que era el rey quien las hacía, o el rey junto a los dioses para que estos luego la pasaran al difunto. La ofrenda en sí era llamada prt-ḩrw ("salida de la voz" u "ofrenda de invocación"), en referencia al rol de la recitación en el acto de proveer sustento al difunto. Incluso si las ofrendas no eran traídas a la tumba con solo recitar la fórmula un visitante mágicamente podía proveer al muerto con comida y bebida.

De modo que se hiciera perpetuo el suministro, cada egipcio debía crear un establecimiento funerario antes de su muerte, en el que se le proveía a una persona o grupo determinadas tierras a cambio de realizar el culto posterior a su muerte y continuamente. Estos individuos eran los sacerdotes del ka (ḥm-k3), habitualmente el hijo mayor del difunto ocupaba esta posición. La creación de establecimientos funerarios fue común durante los reinos antiguos y medio, pero fue sustituido durante el Imperio Nuevo por establecimientos de estatuas. Esto consistía en dedicar estatuas del difunto a un templo y, este, a través de la misma, participaría de las ofrendas y los festivales diarios allí realizados.

Para la gran mayoría de los egipcios, las ofrendas funerarias eran hechas por los propios familiares o por aquellos contratados para asumir el ritual. Para algunos individuos que llegaron a destacar durante la vida, sin embargo, sus cultos funerarios llegaron a ser ostentosos y hasta equiparables con los de las divinidades. La gente común acudía a sus capillas a realizar ofrendas en la esperanza de recibir a cambio bendiciones y favores. El culto en la tumba de Isi, momarca de Edfú durante la dinastía VI continuó por seis siglos después de su muerte. Un amplio templo fue construido en Elefantina durante el Reino Medio en honor al monarca Hekaib, de la dinastía VI.

El culto a estos individuos divinizados era en esencia un asunto local, aunque algunos llegaron a tener relevancia nacional como es el caso de Imhotep, arquitecto jefe del rey Dyeser (dinastía III) que fue adorado como dios de la medicina y la sabiduría durante el período grecorromano, e incluso provisto de un linaje divino. Amenhotep hijo de Hapu, prominente oficial bajo el reinado de Amenhotep III ([[Dinastía XVIII) |dinastía XVIII) fue igualmente adorado durante el período tolemaico con idénticos avatares.

\subsection{El culto al rey difunto:}


Según Donald, 2001 El culto divino del rey comenzaba en vida del mismo, especialmente a partir del Imperio Nuevo, con Amenhotep III. Al igual que una estatua podía ser el receptáculo del ka (espíritu) del difunto, el rey era el recipiente del ka de Horus y por tanto objeto de culto.

Este culto en vida se oficiaba diariamente tras el culto a los dioses en los templos y no puede considerarse culto a la personalidad individual del monarca, sino culto a la divinidad, al concepto de realeza deificada representada por el ka de Horus. Este culto, evidentemente, continuaba tras la muerte.

Desde inicios de la historia egipcia los enterramientos reales incluían un lugar donde el espíritu del monarca podía recibir ofrendas de comida y bebida. La evidencia más antigua del desarrollo de cultos funerarios reales constituyen las edificaciones mortuorias de los reyes predinásticos en Abidos. La pirámide escalonada de Dyeser (Zoser) en Saqqara (dinastía III) es el primer monumento funerario completamente articulado en la que aparecen claramente los conceptos de la divinidad real y los detalles del culto asociado.

Los establecimientos piramidales reales introducidos desde la dinastía IV incluían complejos templarios situados en la zona oriental de la pirámide para el culto del rey difunto, representado por una estatua. Desde la pirámide del rey Userkaf (dinastía V) una estela de falsa puerta se convertiría en el punto focal de las ofrendas al ka del rey difunto. Los reyes de la dinastía XVIII instauraron una nueva forma de enterramiento real, las tumbas excavadas en la roca del Valle de los Reyes en Tebas occidental. En las cercanías, a lo largo de la orilla occidental del Nilo atravesando Karnak, los reyes construyeron estructuras llamadas "templos funerarios" por los egiptólogos, aunque la conveniencia del término ha sido discutida por Gerhard Haeny.

En estos templos el ka del rey difunto continuaría recibiendo las ofrendas, frecuentemente en compañía de Amón y Ra-Horajti. Templos conocidos como "casas de millones de años" fueron construidos por los reyes del Imperio Nuevo como lugares para el culto real antes y después de la muerte. El culto a los reyes difuntos no estaba limitado a los templos estatales: los constructores de tumbas del cercano poblado de Deir el-Medina erigieron capillas a los deificados Amenhotep I y a su madre Ahmose Nefertari, reverenciados como fundadores y patrones de la ciudad y, durante el Reino Medio, los mineros egipcios del Sinaí realizaron el culto del ya fallecido por mucho tiempo rey Seneferu (Keops).

\subsection{Los funerales en la ciudad de Loja:}

Según Reinoso, 2011 Los funerales son los acontecimientos más tristes que suceden en la vida del grupo familiar. Cuentan que, cuando en una familia de la sociedad de Loja ocurría el fallecimiento de una persona adulta, el funeral lo hacían mediante varias ceremonias religiosas. Los deudos de la persona fallecida lo visten con una mortaja que generalmente era un hábito de un religioso (a), o en su defecto los familiares escogían el traje que más le gustaba, o era el más elegante.

Luego lo ubican en una mesa y lo instalan en el salón más grande de su casa, donde le arreglan con flores y cortinas, colocando alrededor de la mesa candelabros con velas encendidas 
y bajo la mesa una fuente de agua, como símbolo de la purificación. Los deudos reciben a las amistades, las condolencias, las ofrendas florales. El difunto es velado toda la noche y al siguiente día se lo lleva a la iglesia para la santa misa en su honor, luego se procede a llevarlo al cementerio para el entierro, en donde se despide trágicamente en medio de lágrimas y lamentos.

En la actualidad los funerales no han variado mucho, ya que en general son los mismos actos y momentos desde que se producen el fallecimiento de una persona; con la diferencia que en nuestros días existen los lugares de velación, en donde se observa mayor solemnidad y con diferentes actos religiosos. El viaje eterno al "parque de los recuerdos" de la persona amada es encabezado por una carrosa muy elegante en donde va el difunto, seguidamente acompañan los familiares más cercanos caminando y el resto de amigos y familiares van en los carros. El fallecimiento y sepelio de los niños son de otra manera.

Los padres del niño (a) lo visten como un ángel, arreglan una sala con flores y cortinas blancas; de azules para los niños y de blancas para las niñas, colocan sobre el ataúd. Lo velan toda la noche, ahí se brindan unos calentados y algo de comer. A la iglesia es llevado y acompañado por niños de su edad y después de la misa en su honor se dirigen al cementerio general.

Tanto en la antigüedad como en la actualidad, el dolor de la pérdida de un niño no es tan grave, porque según dicen que es un ángel que se tiene en el cielo. No así con el fallecimiento de adultos que se guarda el duelo con ropa de color negro por varios meses y hasta por un año. La costumbre de vestirse de negro por varios meses ya se está perdiendo."

\subsection{Formas de entierro:}

"Las formas de entierros se modifican mucho dependiendo de la localidad, y de la cultura a la que pertenecen, pero ahora en la actualidad los entierros varían al gusto de los familiares del fallecido. Existe una gran variedad de formas de entierros como pueden ser los entierros bajo tierra hasta llegar a las incineraciones de los cadáveres para ser depositados en una urna". (Leyton, s.f.)

\subsection{Nichos:}

"Están constituidos por un módulo prismático cuadrangular, hueco, teniendo una sola abertura en su parte frontal mientras que en sus otros extremos se encuentra cerrado. Los nichos se encuentran dimensionados de manera que pueda recibir en su seno al féretro. Esta forma de entierro preferiblemente se lo realiza sobre tierra, de manera que cada nicho se monte sobre el otro y así se optimiza más el espacio". (Leyton, s.f.)

\subsection{Mausoleos:}

Según Leyton, (s/f.). El mausoleo es un monumento funerario y sepulcro señorial. "Etimológicamente proviene del latín: Mausolēum, sepulcro de Mausolo, rey de Caria, quien construyó el famoso Mausoleo de Halicarnaso, una de las llamadas Siete Maravillas del Mundo. Mausolo era uno de los príncipes más ricos y poderosos de su tiempo quien se mandó a construir 
en Halicarnaso un magnífico sepulcro, cuyo esplendor eclipsaba todo lo que en este género se había visto hasta entonces. Los mausoleos respondieron a un sentimiento de transformación de las tumbas en los santuarios, destinados al culto de la memoria del difunto y además sirve de enterramiento para varios miembros de una misma familia.

\subsection{Osarios:}

Según Leyton, (s/f.). Esta forma de entierro tiene como fin reunir o juntar huesos u otras huellas humanas una vez sacadas de su sepultura, para pasar el resto de la eternidad en una antecámara de la tumba. Tienen mucha importancia histórica debido a que es una manifestación de los primeros ritos fúnebres en las comunidades judías más antiguas de Oriente medio.

Los osarios se encontraban cavados en rocas, y se las consideraba sepulturas en el suelo. En Israel a los difuntos se les depositaba en un primer lugar en la cámara exterior de la tumba donde se les envolvía, y se les rociaba con perfume, especies y aceites. Se sellaba con una piedra muy pesada, hasta que quedase cerrada por completo, de este modo se evitaban los saqueos de tumbas. Está compuesto por dos cámaras, una vez que la carne desaparece de los huesos, estos eran recogidos y depositados en una caja pequeña de piedra caliza es decir un osario. La segunda cámara se tallaba pequeños altares o huecos en las paredes para dejar en reposo a estos osarios.

\subsection{Columbarios:}

Según Leyton, (s/f.). A los columbarios se los conoce como nichos destinados a contener las cenizas que se depositan en las urnas. "La palabra columbarium significa propiamente palomar y de su similitud con los palomares proviene este término".

Eran de forma cuadrangular, estos nichos estaban dispuestos en líneas horizontales, separadas por un cimacio. El número de los pisos dependía según la altura de las bóvedas, lo más común eran de ocho o nueve. Cada nicho contenía una o dos urnas cinerarias, de una manera muy apretada donde se utilizaba el inicio y su fin del nicho.

Existía una plancha de mármol, donde se realizaba un grabado con el nombre y otro dato del muerto, esto dependía mucho de la familia del fallecido. Con frecuencia en el interior de los columbarios tenía una ornamentación lujosa, una mezcla de mármol que corría por todo el suelo, mantenía un estuco, ricamente pintada o esculpida.

\subsection{Entierros verdes:}

Según Leyton, (s/f.). Los cementerios verdes se crean a partir de una conciencia ecológica y por la necesidad ambientalmente sostenible frente a los entierros tradicionales de la industria funeraria, donde se preservaba el cadáver y se fabricando ataúdes con materiales muy resistentes.

Los cementerios son diseñados fríamente, con el objetivo primordial en hacer obtener la mayor capacidad posible, y además de ser localizados a las afueras de las ciudades. Si bien, se piensa que la cremación es una manera ecológica, esta tiene una mayor desventaja ya que emite grandes cantidades de humo contaminante con partículas de monóxido de carbono. La industria 
funeraria estadounidense sepulta anualmente junto con los cadáveres, más de 30 millones de toneladas de madera, 1.636.000 toneladas de concreto reforzado, 2.700 toneladas de bronce y cobre 3.130 millones de litros de fluidos, 90.272 toneladas de hierro.

La única alternativa para solucionar estos problemas, es la creación de cementerios verdes donde se utiliza el cadáver generando nueva vida. Existen dos tipos de formas de entierros verdes:

- Suelos de conservación.

Donde se evita modificar el paisaje o el medio ambiente.

- Suelos naturales.

Estos suelos no tienen prioridad para la conservación del paisaje, pero se debe cuidar la composición y nutrientes de suelo, para aprovecharlo en la descomposición del cuerpo. De esta manera los cuerpos pasan a ser parte del bosque y se convierte en fuente de vida para nuevas especies de plantas, animales e insectos. Esta idea nace en Inglaterra, pero hoy ya es adoptado por países como Estados Unidos, Nueva Zelanda y Australia, convirtiéndose en un verdadero ejemplo para otros países, de trasformar el concepto de la muerte ayudando a proteger el ecosistema local. (Leyton, s.f.)

\subsection{Tipos o clases de cementerios:}

Según Quiroa, (s/f.). En la actualidad existe una gran variedad de clases de cementerios, debido a que en el mundo hay varias culturas y religiones, siendo este el factor que originó la creación de las subdivisiones de los cementerios. Es de gran importancia tener en cuenta este tema, debido a que ha llegado a ser importante en el mundo, en el estrato social y económico que se encuentra, es así que ha llegado a tal punto que existe cementerios para cada una de las diferentes clases sociales.

\section{$\checkmark$ Por su administración}

- Cementerios oficiales: Administrados por la municipalidad, ellos serán los encargados de operar dicho cementerio.

- Civiles generales: Todo tipo de inhumaciones de cadáveres, restos humanos y restos humanos áridos o cremados serán sepultados, no importa el origen del fallecido.

- Civiles delegacionales: Se encuentran en municipios o en departamentos, en ellos se inhuma a los cadáveres procedentes del área o de la zona de la delegacional.

- Civiles vecinales: Son aquellos en los que se podrán inhumar cadáveres, restos humanos áridos o cremados procedentes de áreas vecinas.

- Cementerios concesionados: Administrados por personas particulares, de nacionalidad de país al que pertenecen.

- Mixtos: Estos cementerios están a cargo tanto de los entes privados y gubernamental.

\section{$\checkmark$ Por la religión}


Los conceptos religiosos son un punto clave que determina el concepto de la forma de entierro de los individuos, generando así una clasificación de tumbas por religiones. A los cementerios se los diseñan según los principios filosóficos que tenga cada religión.

- Católicos: Su teología, doctrina, liturgia, principios éticos y características y normas de comportamiento, gira alrededor de un todo. La principal característica distintiva del cementerio católico es el reconocimiento de la autoridad y primacía del Papa, obispo de Roma.

- Protestantes: Se trata de una de las principales divisiones de la cristiandad, junto con las Iglesias Ortodoxas orientales, las Iglesias Ortodoxas occidentales y el catolicismo. Las doctrinas de las diversas ramas protestantes varían, pero son prácticamente unánimes en la que implica una relación personal directa del individuo con Dios sin ninguna institución.

- Judíos: La más antigua de las tres religiones monoteístas más difundidas junto con el cristianismo y el islam, su práctica se basa en las enseñanzas de la Torá. El rasgo principal de la fe judía es la creencia en un Dios omnisciente, omnipotente y providente, que habría creado el universo y elegido al pueblo judío para revelarle la ley contenida en los Diez Mandamientos. Otra característica que diferencia de las otras religiones, es que se considera no sólo como una religión, sino también como una tradición y una cultura.

\section{$\checkmark$ Por grupo social}

El lugar donde se va hacer enterrado no es de importancia, existe en la actualidad situaciones culturales que determinan el lugar o sitio. En el Ecuador existe cierta clasificación de cementerios según clase social.

- Cementerios para clase social media y baja: Estos cementerios por lo general, se encuentran administrados o son de propiedad del estado o municipalidad. Se encuentran limitados por muchos factores que influyen en el desarrollo del campo santo, como es el factor económico.

- Cementerios estatales: De la misma manera que los cementerios de clase media y baja, estos se encuentran manejados por el estado.

- Cementerios militares: Cementerios que se encuentran principalmente en territorio de la Unión Europea y Rusia. Estos cementerios se tratan simplemente de sepultar exclusivamente de miembros de las fuerzas armadas del país.

- Cementerios privados: Los conceptos utilizados arquitectónicos y urbanísticos bajo los cuales se han desarrollado los cementerios privados y las ideas de los proyectistas pueden ser aplicados como los Cementerios públicos o municipales.

\section{$\checkmark$ Como elemento constructivo}

Se alimenta de manera muy rica por medio del diseño y las técnicas constructivas para lograr alcanzar su meta.

- Horizontal: Espacio donde se depositan cadáveres bajo tierra, puede haber un ataúd o apilamiento de varios de ellos.

- Vertical: Está constituido por uno o más edificios, con gavetas sobrepuestas para el depósito de cadáveres, restos humanos áridos o cremados. 
- Columbario: Cuya estructura está constituida por un conjunto de nichos destinados al depósito de restos humanos.

\section{$\checkmark$ Como elemento paisajista.}

Se lo representa como un lugar natural de un contexto que representa la forma del paisaje.

- Parque cementerio: Constituido por jardines de vegetación exuberante.

- Bosque: Los árboles son los elementos principales, se tiene una consideración con el paisaje natural, la topografía contrasta con el entorno y la arquitectura es paisajista.

- Arquitectónico: Es la organización de monumentos, grupos de tumbas, ayudándose con la vegetación.

- Jardín: El concepto primordial es en armonizar grupos de jardines con vegetación (árboles, arbustos, plantas) que se separan con caminos (vehiculares, peatonales). Se concibe valiéndose de la arquitectura paisajista.

\subsection{Impacto de cementerios en el medio ambiente:}

Según Reyes, 2011 Los cementerios pueden llegar hacer un peligro para el medio ambiente y para la salud de las persona si no se toma las medidas adecuadas, la mineralización de las partes orgánicas de los restos humanos, son los que propician la formación de olores desagradables y de sustancias portadoras de gérmenes patógenos, y se permite que sean percibidos por los pobladores que habitan a su alrededor o que los líquidos generados lleguen a disponerse en las fuentes de abastecimiento de agua superficiales o subterráneas usadas para el consumo humano"

La cantidad de emanación de este líquido, cuyo nivel de toxicidad depende de la presencia de compuestos orgánicos y de la carga virtual patogénica del cuerpo humano, puede llegar hasta los 40 litros por cada adulto de 70 kilos de peso. Su constitución comprende: $60 \%$ de agua, $30 \%$ de sales minerales y $10 \%$ de sustancias complejas, poco conocidas, tales como la putrescina, y la cadaverina.

Por la generación de lixiviados que son los resultados de la descomposición de cuerpos sepultados bajo suelo en las necrópolis, por todo esto y por las características del suelo, es que existe riesgo de contaminación de aguas subterráneas, debido a la emanación de los desechos sólidos provenientes de sepulturas de cadáveres bajo suelo, además que existe una escasa información existente sobre este tema, desinterés de la entidad normativa de nuestro país y de los propietarios de este tipo de cementerios. Es por este motivo que genera una gran responsabilidad la construcción de un cementerio, debido a muchos factores ambientales y de salud."

\subsection{Herencia sefardita y costumbres funerarias:}

Según Chiriboga, 2016. Las costumbres fúnebres de los sefarditas y los lojanos sorprenden con sus similitudes, hasta hace algunos años los lojanos luego de que fallecían sus familiares procedían de la siguiente manera: al difunto lo despojaban de alhajas, adornos y calzado, posteriormente era amortajado con una sábana nueva y se lo ponía en un ataúd sumamente sencillo que solía ser de tablas sin cepillar cubierto de un paño nuevo, y a la cabecera 
del mismo se colocaba un cirio para que acompañe al cadáver. Inmediatamente después del fallecimiento se enlutaba la casa, se retiraban los cuadros y se cubrían los muebles con tela negra, en el portón se colocaba un cortinaje negro y crespón que anunciaban el luto.

En las puertas de las casas de los familiares de difunto se colocaban lazos que indicaban el duelo, los mismos que se mantenían durante un año en la casa del difunto y ocho días la de los parientes.

Monseñor Ángel Rogelio Loayza Serrano relata que posterior al entierro se rezaba y velaba ocho días en la casa del fallecido, transcurrido ese tiempo se realizaba los ritos de aseo y pureza, las pertenencias del difunto eran separadas y su ropa sacada de sus armarios para proceder la ceremonia especial llamada "el lavatorio" el cual se realizaba en aguas corrientosas como ríos o quebradas a la concurrían parientes y amigos para colaborar, luego de treinta días de luto se realizaba la misa por el descanso de su alma, y a los doce meses de fallecido se celebraba la misa y la colocación de la lápida.

En áreas rurales del cantón estas aún se preserva estas costumbres funerarias. El Sr. Franco Eras Días menciona que durante la agonía y expiración de la persona los familiares cantan salmos, luego del deceso la persona era colocada dentro de su ataúd en el suelo, donde son sellados con cera los oídos, ojos, nariz y boca para que no ingresen bichos a su cuerpo, para finalizar se los cubre con una sábana blanca encendiendo una vela en su cabecera.

Hace una década, en los pueblos y cantones el cuerpo del fallecido era amortajado y cubierto con una sábana, para depositado en ataúdes sencillos hechos de cuatro tablones, lo que se sellaban rápidamente con clavos y se los colocaba sobre dos sillas, una al comienzo y otra a los extremos, aunque según Franco Eras Díaz, las personas que viven en los pueblos amortajan los cuerpos los cubren con una sábana blanca y finalmente lo depositan en la tierra.

Los campesinos blancos antes de amortajar y enterrar a sus fallecidos los llevaban a quebradas para lavarlos, estas costumbres han sido observadas en sitios de la provincia de Loja, como Jimbilla según el Dr. Oswaldo Espinosa Sigcho. El Sr. Franco Eras Díaz que ya ha presenciado varios rituales fúnebres del Cantón Loja, comenta que, durante la agonía de la persona se canta la canción católica Santo, Santo, Santo, que cuyo significado en hebreo es Kadosh, Kadosh, Kadosh.

Estas mismas costumbres se ven reflejadas en pueblos marroquíes de descendencia sefaradí, resultando por lo tanto paradójico el saber que estas son también practicadas y de manera exacta en la Provincia de Loja.

\section{Fase 2: Registro de Información mediante una ficha de inventario}

Para la elaboración de las fichas técnicas de los cementerios, criptas y camposantos (caso de estudio cantón Loja); se dividió las parroquias urbanas y rurales, y se recabo la información en dos fases: en la primera fase se levantó la información de las criptas, cementerios y camposantos las parroquias urbanas mediante fichas y entrevistas; en la segunda fase se levantó la información de los cementerios de las parroquias rurales mediante observación directa, y entrevistas a los pobladores y administradores que en su mayoría resultaron los síndicos de las 
parroquias, en las dos fases se tomó en consideración la siguiente información: categoría, tipo, subtipo, provincia, cantón, parroquia, ubicación, coordenadas, estado de conservación, extensión, descripción, costos, administrador.

\section{Diagnóstico:}

De acuerdo con el diagnóstico realizado en las seis parroquias urbanas y las trece parroquias rurales, se llegó a la conclusión de que la mayoría de cementerios se encuentran en malas condiciones, debido a la falta de administración en algunos casos y en otros la falta de apoyo de los gobiernos parroquiales, los mismos que no velan por su mantenimiento ni conservación, otro de los factores por el cual los cementerios no se mantienen es el bajo o inexistente coste de sus servicios, lo que no les permite construir vías de acceso, capillas, parqueaderos, baterías sanitarias, o el mantenimiento de la estructura; en la mayoría de parroquias se notó cierta resistencia por parte los pobladores a la ayuda del gobierno Municipal, ya que temen el alza de costes del servicio, en muchos otros se identificó que el acceso a los cementerios era malo, teniendo que caminar con el fallecido grandes distancias para su sepultura, además algunos cementerios no tenían administradores o en la mayoría de casos esta actividad desempeña el síndico, quien no gana ninguna remuneración; en el caso de las criptas la mayoría de estas se encuentran en malas condiciones debido a la falta de mantenimiento.

\section{Fase 3: Elaboración de un inventario de las criptas, cementerios y campo santos}

Para le realización del inventario se tomó en consideración información importante a partir de las fichas técnicas que se detallan en la fase 2; como: nombre del cementerio, cripta o camposanto de estudio, parroquia en la que se encuentra, extensión y estado de conservación.

\begin{tabular}{|c|c|c|c|c|}
\hline \multicolumn{5}{|c|}{ Inventario de cementerios y criptas y camposantos (caso de estudio cantón Loja) } \\
\hline $\mathbf{N}^{\circ}$ & Nombre del Cementerio & Parroquia & Extensión & $\begin{array}{c}\text { Estado de } \\
\text { conservación }\end{array}$ \\
\hline 1 & Cementerio de Yanacocha & El Valle & $21.818 \mathrm{~m} 2$ & Bueno \\
\hline 2 & Cementerio Parque los Recuerdos & Punzará & $151.202 \mathrm{~m} 2$ & Muy bueno \\
\hline 3 & Campo Santo Jardines del Zamora & Punzará & 3.5ha & Excelente \\
\hline 4 & Cementerio de Obrapía & Sucre & $20.004 \mathrm{~m} 2$ & Bueno \\
\hline 5 & Cementerio de Motupe & Carigán & $48.000 \mathrm{~m} 2$ & Malo \\
\hline 6 & Cementerio de Vilcabamba & Vilcabamba & $19.829,71 \mathrm{~m} 2$ & Bueno \\
\hline 7 & Cementerio de Gualel & Gualel & 2,5ha & Malo \\
\hline 8 & Cementerio de El Cisne & El Cisne & 10 ha & Bueno \\
\hline 9 & Cementerio de Chiquiribamba & Chuquiribamba & 1ha y media & Malo \\
\hline 10 & Cementerio de Chantaco & Chantaco & 2 ha. & Malo \\
\hline 11 & Cementerio de Santiago & Santiago & 1ha. & Bueno \\
\hline 12 & Cementerio de San Lucas & San Lucas & 2ha. & Bueno \\
\hline 13 & Cementerio de Jimbilla & Jimbilla & $5000 \mathrm{~m} 2$ & Malo \\
\hline 14 & Cementerio de Taquil & Taquil & $120 * 2.50$ & Bueno \\
\hline 15 & Cementerio de Yangana & Yangana & $2000 \mathrm{~m} 2$ & Bueno \\
\hline
\end{tabular}




\begin{tabular}{lllll}
\hline $\mathbf{1 6}$ & Cementerio de Quinara & Quinara & $2400 \mathrm{~m} 2$ & Bueno \\
$\mathbf{1 7}$ & Cementerio de San Pedro de Vilcabamba & San Pedro de Vilcabamba & $4905.55 \mathrm{~m} 2$ & Bueno \\
$\mathbf{1 8}$ & Cementerio de Malacatos & Malacatos & $2000 \mathrm{~m} 2$ & Muy bueno \\
$\mathbf{1 9}$ & Criptas de la Iglesia San Francisco & El Sagrario & Se desconoce Malo \\
$\mathbf{2 0}$ & Criptas de la Iglesia Catedral & El Sagrario & Se desconoce Excelente \\
$\mathbf{2 1}$ & Criptas de la Iglesia de Santo Domingo & El Sagrario & Se desconoce Malo \\
$\mathbf{2 2}$ & Criptas de las Madres Concepcionistas & El Sagrario & Se desconoce Bueno \\
$\mathbf{2 3}$ & Criptas de la Iglesia Perpetuo Socorro & El Sagrario & Se desconoce Mala \\
\hline
\end{tabular}

Fuente: Entrevista

Elaborado por: Los Autores, 2016

\section{Fase 4: Estudio de la capacidad instalada y utilizada:}

Capacidad instalada: La capacidad instalada es la capacidad que soporta el terreno para recibir fallecidos

$$
\text { Fórmula: Capacidad instalada }=\frac{\text { superficie total del terreno }}{\text { superficie ocupada por fallecido }}
$$

Capacidad utilizada: se la halla en función a la defunción por los días laborales, por meses del año laborales

Fórmula: Capacidad utlizada $=$ número de fallecidos que ingresan al año al cementerio $x$ dias laborables $x$ meses del año

Obtención de la capacidad instada y utilizada (caso de estudio cantón Loja)

Capacidad instalada: La capacidad instalada es la capacidad para recibir fallecidos en el campo santo, sin verse afectado.

Obtención de la capacidad instalada.

\begin{tabular}{rrrr}
\hline \multicolumn{4}{c}{ Capacidad instalada } \\
\hline Años & capacidad instalada & porcentaje a ocupar & capacidad utilizada \\
& & & \\
$\mathbf{1}$ & 2500 & $80 \%$ & 600 \\
$\mathbf{2}$ & 2000 & $85 \%$ & 700 \\
$\mathbf{3}$ & 2125 & $90 \%$ & 800 \\
$\mathbf{4}$ & 2250 & $95 \%$ & 800 \\
$\mathbf{5}$ & 2375 & $100 \%$ & 100 \\
\hline \multicolumn{4}{c}{}
\end{tabular}

A continuación, se calcula la capacidad instalada del campo santo ecológico:

$$
\begin{gathered}
\text { Capacidad instalada }=\frac{\text { superficie total del terreno }}{\text { superficie ocupada por fallecido }} \\
\text { capacidad instalada }=\frac{10,000}{4}=2,500
\end{gathered}
$$


A partir de esta fórmula se toma en cuenta que el campo santo va ir ocupando un $5 \%$ de su capacidad anualmente, llegando a ocupar su capacidad máxima al quinto año. Capacidad utilizada: Sirve para determinar la cantidad de fallecidos anuales que llegarán al cementerio, tomando en consideración la tasa de mortalidad.

Capacidad utlizada
$=$ numero de fallecidos que ingresan al año al cementerio $x$ dias laborables $x$
meses del año
capacidad instalada $=5$ fallecidos $x$ 30dias $x 12$ meses $=1800$

\section{Discusión}

En base al catastro de establecimientos fúnebres que se realizó, se concluye que las parroquias urbanas y rurales cuentan con la infraestructura para la prestación de los servicios fúnebres, sin embargo, se deberían realizar modificaciones que se adapten a los requerimientos de los consumidores, además de darles un mayor mantenimiento.

Es indispensable brindar capacitaciones a los trabajadores de estos establecimientos para un mejor manejo y administración, con el fin de mejorar los servicios ofertados.

Después de haber realizado el diagnóstico de los establecimientos fúnebres, se obtuvo como resultado un total de 11 cementerios de parroquias se encuentran en malas condiciones, mientras seis de ellos se hallan en buenas condiciones, el campo santo se encuentra en excelentes condiciones, y 1 de las criptas están en buenas condiciones, no obstantes 3 de las criptas tiene un estado de conservación muy malo.

Al realizar el cálculo de la capacidad instada se determina que el terreno puede admitir por cada 10 ha una cantidad de 2500 fallecidos, sin embargo, se prevé según los índices de mortalidad en los sectores de estudio, que su capacidad máxima se cubrirá en aproximadamente cinco años.

Para realizar la capacidad utilizada se tomó en consideración la cantidad de fallecidos, por los días de mes y por los meses del año obteniendo así un valor de 1800 fallecidos de acuerdo a la tasa de defunción, que posiblemente utilizaran los servicios fúnebres en el cantón Loja.

\section{Bibliografía}

Catamayo, m. (01 de Diciembre de 2016). http://www.multicanalcatamayo.com. Obtenido de http://www.multicanalcatamayo.com/video-funeraria-jaramillo-inauguro-camposantojardines-de-zamora/

Donald, R. (2001). The Oxford Encyclopedia of Ancient Egypt. Vol. I. (Vol. Vol. I.). Oxford: Encyclopedia of Ancient Egypt. 
Eche, E. (2001). Evaluación de Impacto ambiental de un cementerio tipo parque ecológico (Vol. 4). Lima, Perú.

ECUMENOPOLIS, \& Huyuk”., “. e. (s.f.). http://ojoeternidad.blogspot.com. Obtenido de http://ojoeternidad.blogspot.com/2007/09/

espirituales, E. d. $\quad$ (s.f.). Obtenido de http://www.palermo.edu: http://www.palermo.edu/cienciassociales/publicaciones/pdf/Psico3/3Psico\%2009.pdf

Fierro, H. D. (2003). Los sonidos de nuestro mundo. D.F Mexico : Direccion general de divulgacion de la ciencia.

Flores, K. M. (s.f.). Los Cementerios Como Fenómeno Social.

GADMLoja. (2013). Municipio de loja. Recuperado el 09 de mayo de 2016, de http://www.loja.gob.ec/files/pdot/introduccion.pdf

Jiménez, R. I. (12 de 2012). Historia de los cementerios. ARQHYS.

León, A. C. (2005). utpl.edu.ec. Obtenido de http://dspace.utpl.edu.ec/handle/123456789/14635

Leyton, F. $\quad$ (s.f.). http://ecosofia.org. Obtenido de http://ecosofia.org/2006/07/cementerios_entierros_verdes.html

Loja, M. d. (20 de Noviembre de 2016). http://www.loja.gob.ec. Obtenido de htt

MAE. (2015). http://www.ambiente.gob.ec/. Recuperado el 10 de mayo de 2016, de http://www.ambiente.gob.ec/ecuacion-del-medio-ambiente/

Mariano Seoanez Calvo, I. A. (1997). El Medio Ambiente en la Opinion Publica. Barcelona: Ediciones Mundi-Prensa.

Muerte, L. R. (s.f.). http://www.sanjosedemoro.pucp.edu.pe. Obtenido de http://sanjosedemoro.pucp.edu.pe/descargas/articulos/LosMochicasMuerte.pdf

Municipio de Loja. (09 de Diciembre de 2016). http://www.loja.gob.ec. Obtenido de http://www.loja.gob.ec/contenido/santiago

Municipio de Loja. (10 de Diciembre de 2016). http://www.loja.gob.ec. Obtenido de http://www.loja.gob.ec/node/167

Municipio de Loja. (21 de Noviembre de 2016). http://www.loja.gob.ec. Obtenido de http://www.loja.gob.ec/node/6802

Municipio de Loja. (03 de Diciembre de 2016). http://www.loja.gob.ec. Obtenido de http://www.loja.gob.ec/node/177 
Municipio de Loja. (03 de Diciembre de 2016). http://www.loja.gob.ec. Obtenido de http://www.loja.gob.ec/node/6803

Municipio de Loja. (04 de diciembre de 2016). http://www.loja.gob.ec. Obtenido de http://www.loja.gob.ec/contenido/vilcabamba

Municipio de Loja. (05 de diciembre de 2016). http://www.loja.gob.ec. Obtenido de http://www.loja.gob.ec/node/163

Municipio de Loja. (06 de Diciembre de 2016). http://www.loja.gob.ec. Obtenido de http://www.loja.gob.ec/contenido/el-cisne

Municipio de Loja. (07 de Diciembre de 2016). http://www.loja.gob.ec. Obtenido de http://www.loja.gob.ec/node/161

Municipio de Loja. (08 de Diciembra de 2016). http://www.loja.gob.ec. Obtenido de http://www.loja.gob.ec/contenido/chantaco

Municipio de Loja. (12 de Diciembre de 2016). http://www.loja.gob.ec. Obtenido de http://www.loja.gob.ec/node/164

Municipio de Loja. (12 de Diciembre de 2016). http://www.loja.gob.ec. Obtenido de http://www.loja.gob.ec/node/164

Municipio de Loja. (15 de Noviembre de 2016). http://www.loja.gob.ec. Obtenido de http://www.loja.gob.ec/contenido/yangana

Municipio de Loja. (17 de Diciembre de 2016). http://www.loja.gob.ec. Obtenido de http://www.loja.gob.ec/contenido/quinara

Municipio de Loja. (18 de Diciembre de 2016). http://www.loja.gob.ec. Obtenido de http://www.loja.gob.ec/node/168

Municipio de Loja. (20 de Diciembre de 2016). http://www.loja.gob.ec. Obtenido de http://www.loja.gob.ec/node/168

Municipio de Loja. (21 de diciembre de 2016). http://www.loja.gob.ec. Obtenido de http://www.loja.gob.ec/node/175

Pascual, E. (11 de septiembre de 2015). el blog verde. com. Recuperado el 10 de mayo de 2016, de http://elblogverde.com/la-contaminacion/

Pilco, F. (Noviembre de 2012). http://repositorio.ug.edu.ec/. Recuperado el 10 de mayo de 2016, de http://repositorio.ug.edu.ec/bitstream/redug/1952/1/La\%20contaminaci\%C3\%B3n\%20a mbiental\%20y\%20el\%20desempe $\%$ C3\%B1o\%20institucional\%20del\%20instituto\%20te cnol\%C3\%B3gico\%20superior\%20Sim\%C3\%B3n\%20bolivar.pdf 
Porto, J. P. (2016). Definicion.de. Obtenido de http://definicion.de/cementerio/

Quiroa, L. (s.f.). http://cementeriosymas.blogspot.com. Obtenido de http://cementeriosymas.blogspot.com/2013/04/cementerios-y-sus-clasificacion-un.html

Ramos, E. (1 de julio de 2008). http://www.gestiopolis.com/. Recuperado el 11 de Mayo de 2016, de http://www.gestiopolis.com/metodos-y-tecnicas-de-investigacion/

Reinso, Á. J. (s.f.). Costumbres Y Tradiciones Del Cantón Loja.

Susan, P. (1999). Mesopotamia antiguo el Edén que nunca estaba" . Cambridge: Prensa de la universidad de Cambridge . Obtenido de "Mesopotamia antiguo el Edén que nunca estaba".

Twenergy. (06 de abril de 2012). http://twenergy.com/. Recuperado el 10 de mayo de 2016, de http://twenergy.com/a/tipos-de-contaminacion-525

VALOR, D. D. (2012). http://www.dspace.unia.es. Obtenido de http://dspace.unia.es/bitstream/handle/10334/2222/0364_Fenoglio.pdf?sequence=1

\section{Apendix}

Ficha de resumen de los cementerios de las parroquias urbanas (caso de estudio cantón Loja)

Ficha cementerio Parque Los Recuerdos

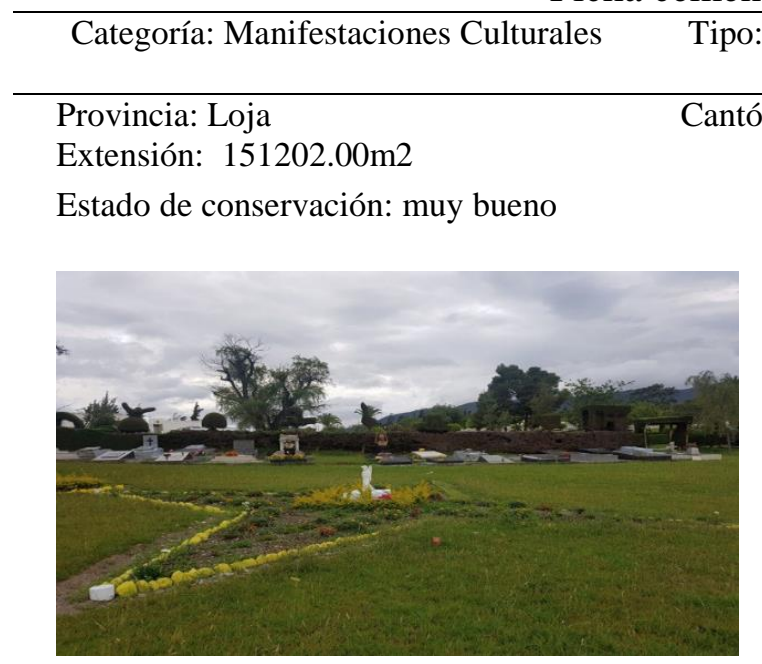

Subtipo: Manifestaciones Religiosas,

Tradicionales y Creencias Populares

Provincia: Loja

Parroquia: Punzará

Ubicación: Sur Oeste de la ciudad, en la Av. Pio

Estado de conservación: muy bueno

Jaramillo Alvarado.

Coordenadas: $-4.019036,-70.206073$

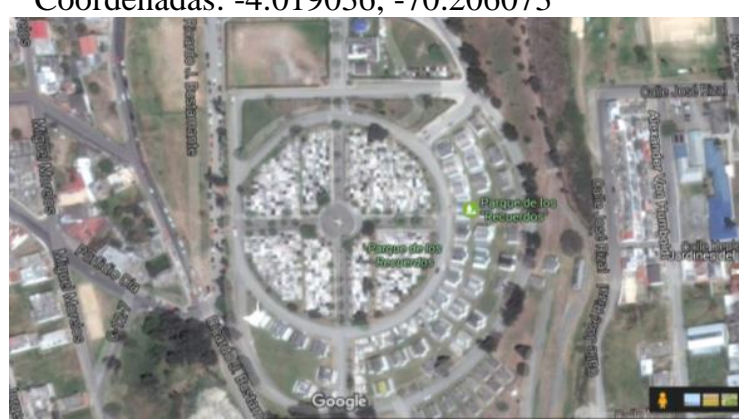

Fuente: Google Mapas

Descripción: el cementerio cuenta con 1436 tumbas construidas de las cuales 540 tumbas son de inhumaciones en tierra, existen 3013 bóvedas, 1498 Nichos, un total de 80 mausoleos divididos en 3 zonas (cuyas denomina son: zona $\mathrm{C}$, zona $\mathrm{D}$, zona $\mathrm{E}$ ), en la zona $\mathrm{C}$ hay 26 mausoleos, en la zona $\mathrm{D}$ existen 30 mausoleos y en la zona $\mathrm{E}$ hay un total de 34 mausoleos, además de 3 áreas de jardinería, 1 de Baterías Sanitarias, 2 accesos, 10 áreas saturadas de tierra, 1 capilla, área de velaciones, y área de sepultura de hombres ilustres. Los servicios que presta el cementerio son de Arriendo, Exhumación, inhumación y renovación de cadáveres, y un servicio particular de cremación.

Costos: Los costos de arriendo de las Bóveda del cementerio es de 235,09 por cinco años, de las tumbas son de 235, 09 por cinco años, mientras que del nicho es de 100, 91 por cinco años; los costos de renovación 235,09 la bóveda por cinco años, de las tumbas son de 235, 09 por cinco años, y del nicho es de 100, 91 por cinco 
años; los costos de exhumación varían para el primer mes es de 1,68 y por cinco años de 100,91 en adultos, y en niños de 1 mes 3,36 mientras que para cinco años es de 231,35. El cementerio cuenta con un servicio privado adicional de cremación, para quienes tiene 21 años en delante de fallecidos es de 198,00; para quienes tienen de 16 a 20 años de fallecidos es de 220,00; para quienes tiene de 11 a 15 años de fallecidos es de 275,00; para quienes tienen de 6 a 10 años de fallecidos es 440,00; y para los que tienen de 2 a 5 años de fallecidos 550,00 .

Especies vegetales utilizadas:

Cupressus macrocarpa (Cipre),

Euphorbia pulcherrima (Estrella de Panamá)

Chionanthus pubescens (Arupo)

Retama Sphaerocarpa (Retama)

Acacia macracantha (Faique)

Administración del cementerio: Leonardo Maldonado Armijos

Fuente: Entrevista

Elaborado por: Los Autores, 2016

Ficha de resumen de los cementerios de las parroquias rurales (caso de estudio cantón Loja) Cementerio de Chuquiribamba "San Juan Bautista"

Fuente: Entrevista

Elaborado por: Los Autores, 2016

Ficha de resumen de un campo santo de las parroquias urbanas (caso de estudio cantón Loja)

Tipo: Etnografía

Subtipo: Manifestaciones Religiosas, Tradicionales y Creencias Populares

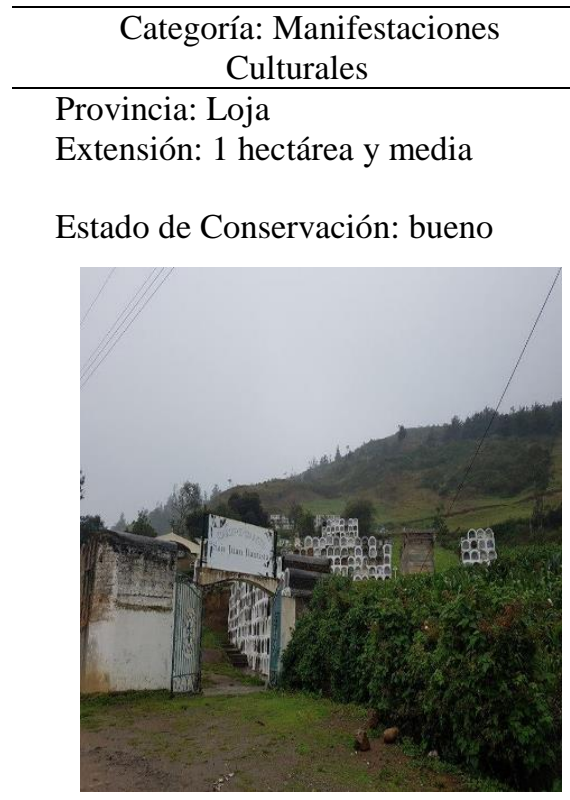

Provincia: Loja

Extensión: 1 hectárea y media

Estado de Conservación: bueno

Descripción: EL cementerio se encuentra administrado por el Síndico Vidal Caraguay, es uno de los cementerios más antiguos del cantón Loja, datando de aproximadamente 200 años, en un principio solo se realizaban sepulturas en tierra, donde hay aproximadamente 3000 difuntos; en lo posterior se construyeron las bóvedas actualmente existen cerca de 2000.

Los servicios que presta el cementerio son de inhumación, exhumación y arriendo

Costos: Los costos para la sepultura en tierra son de 30 dólares, mientras que los costos de las bóvedas son de 200 dólares, el cobro solo se lo realiza una vez y no existe costo por renovación

Administración del cementerio: Sacristán Alcides Medina, Sindico Vidal Caraguay 
Ficha Campo Santo Jardines del Zamora

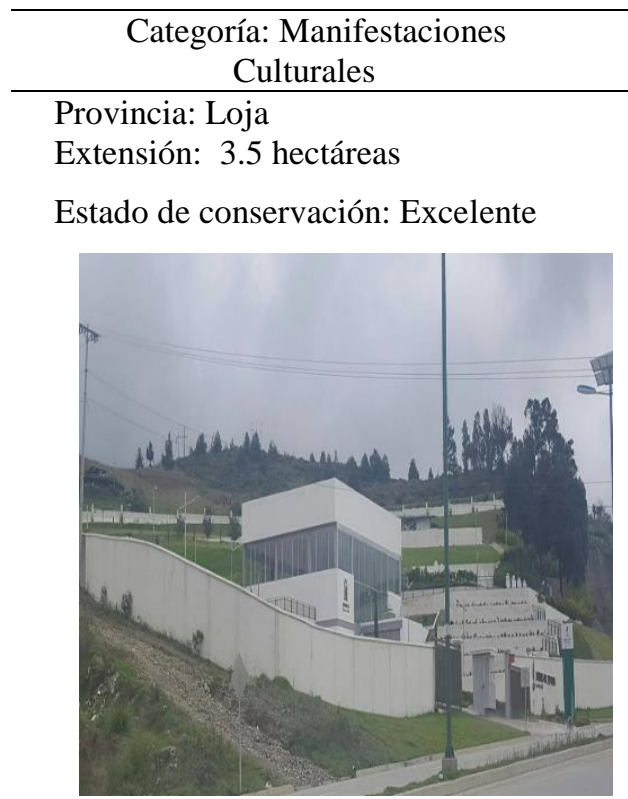

Tipo: Etnografía

Cantón: Loja

Subtipo: Manifestaciones Religiosas, Tradicionales y Creencias Populares

Ubicación: Avenida de Integración Barrial Ángel Felicísimo Rojas

Coordenadas: $-4.0250124,-79.2188278,18$

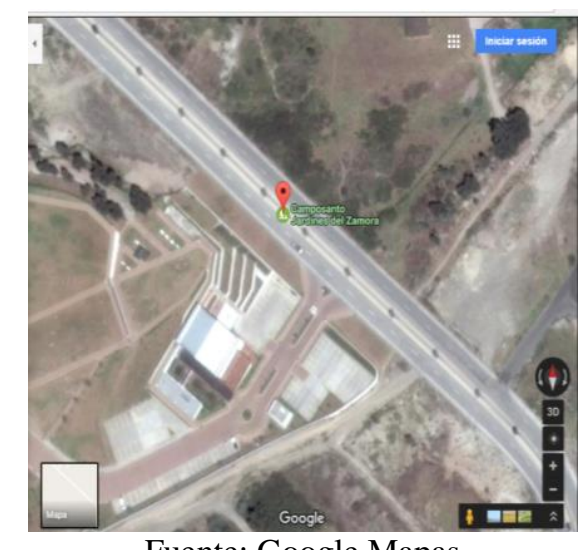

Fuente: Google Mapas

Descripción: El área de sepulturas bajo tierra está dividida en 3 niveles con capacidad para 2250 unidades de sepultamiento, el nivel uno, consta de 204 unidades, el nivel dos, de 600 unidades y el nivel tres de 1368 unidades, otras áreas cuentan con 78 unidades. Los nichos sobre tierra tienen una capacidad de 600 bóvedas para inhumación, Osarios y cinerarios, tiene una capacidad de 550 unidades. Los panteones familiares se dividen en 2 secciones, la primera de 80 unidades y segunda sección con 39 unidades, dando un total de 119 panteones familiares. Los mausoleos familiares, tienen un diseño dúplex, con un total de 21 unidades. Mientras que los nichos para instituciones, tiene una capacidad para 450 unidades de sepultamiento.

Costos: Los servicios de cremación de cuerpos y restos tienen un costo de 600 dólares, las urnas de cenizas a elección estándares y ecológicas tiene un costo de 70 a 100 dólares, los servicios del Bosque Memorial tienen un precio de 1860 dólares, mientras que los nichos en pared cuestan 1360 dólares, los nichos cinerarios tienen un precio de 1710, y los espacios en jardín para dos cuerpos tiene un costo de 3640, el alquiler de bóvedas es de 600 dólares durante 4 años y su costo de renovación es de 450 dólares.

Administración del cementerio: Rosa Viñan Benavidez

\section{Fuente: Entrevista}

Elaborado por: Los Autores, 2016

Ficha de resumen de las criptas de las parroquias urbanas (ficha de estudio cantón Loja) Ficha Cripta de la Catedral

\begin{tabular}{ccc}
\hline Categoría: Manifestaciones Culturales & Tipo: Etnografía & $\begin{array}{c}\text { Subtipo: Manifestaciones Religiosas, } \\
\text { Tradicionales y Creencias Populares }\end{array}$ \\
\hline Provincia: Loja & Cantón: Loja & Parroquia: El Sagrario \\
\hline
\end{tabular}




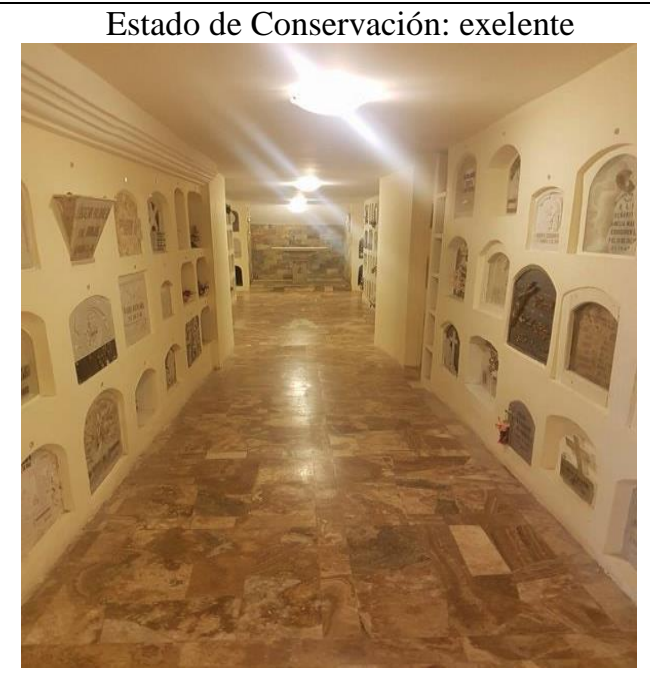

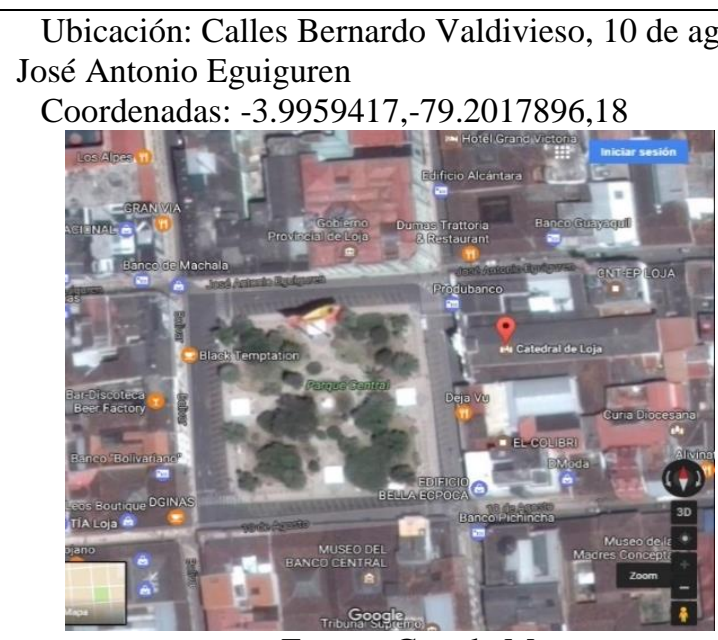

Fuente: Google Mapas

Descripción: Los cimientos de La Catedral se construyen con la fundación de Loja junto con las criptas, que se construyeron en dos etapas: la primera se construyó junto al templo y la segunda en los años 1987 a 1990 donde se dio mayor solidez a los cimientos y se construyó una nueva en la parte bajo el altar principal de 15 bóvedas, la cual es solo para obispos. Tiene 361 sitios de enterramiento, de los cuales 23 están vacíos, 15 están destinados para bóvedas y 323 para nichos.

Costos: El arriendo perpetuo del nicho o bóveda es de $\$ 3500$

Diseño de la cripta:

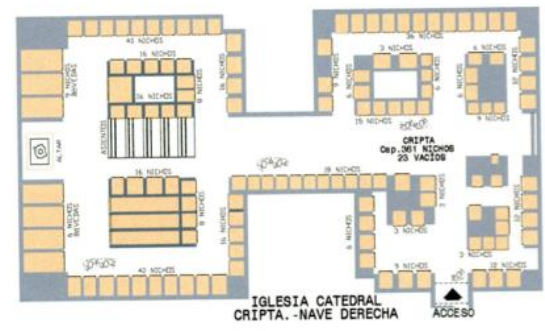

Administración del cementerio: Párroco Jimmy Arias

Fuente: Entrevista

Elaborado por: Los Autores, 2016 